\title{
Neonatal Outcomes of Immigrant and Turkish Preterm Infants Treated in a Level-3 Neonatal Intensive Care Unit: A Retrospective Study
}

\author{
(1) Nuriye Tarakçı, (1) Fatma Hilal Yılmaz, (1) Hüseyin Altunhan \\ Necmettin Erbakan University, Meram Faculty of Medicine, Department of Neonatology, Konya, Turkey
}

\begin{abstract}
Aim: To evaluate the neonatal outcomes of immigrant preterm babies and compare them with Turkish preterm babies in a Neonatal Intensive Care Unit (NICU).

Materials and Methods: The present study was conducted using a retrospective design in the NICU of Necmettin Erbakan University between October 2015 and October 2019. Antenatal, natal and postnatal outcomes of the premature infants were evaluated and compared.

Results: Maternal age ( $p<0.001)$, antenatal follow-up $(p<0.001)$, antenatal steroid use $(p<0.001)$, patent ductus arteriosus (PDA) ( $p=0.03)$ and bronchopulmonary dysplasia (BPD) $(p=0.05)$ were statistically higher in the Turkish patients. Additionally, the rates of breastfeeding ( $<<0.01)$ and kangaroo mother care $(p<0.01)$ were found to be higher among Turkish mothers. On the other hand, the necrotizing enterocolitis (NEC) rate $(p=0.002)$ was found to be higher among immigrant babies. Duration of mechanical ventilation and oxygen supply were similar for both groups; however, the duration of nasal-continuous positive airway pressure use was longer in the Turkish patients ( $p=0.01$ ).

Conclusion: In this study, immigrant mothers were younger than their Turkish counterparts and their antenatal follow-ups were insufficient. The rate of hospitalization in a NICU and NEC rates were higher in immigrant preterm infants, respiratory distress syndrome, PDA and BPD were more commonly encountered in Turkish preterm infants.
\end{abstract}

Keywords: Newborn, migration, refugees, preterm, Turkey

\section{Introduction}

The number of refugees who leave their home country due to civil wars in Middle Eastern countries has been increasing gradually over the years. In parallel with low socioeconomic status, unhealthy living conditions and an increased birth rate among these immigrants, health issues are also increasing. There have been many studies that investigated the perinatal status of the global immigrant population, and their findings revealed that having an immigrant status is related to insufficient antenatal care, perinatal mortality, prematurity, low birth weight (BW) and congenital anomalies (1-4). In addition to individual/patientassociated factors in host and immigrant populations, inequality and variability in healthcare access are factors that contribute to the poor perinatal outcomes of the immigrant population.

In the literature, studies that describe perinatal outcomes of immigrant populations have been published.

\section{Address for Correspondence}

Nuriye Tarakçı MD, Necmettin Erbakan University, Meram Faculty of Medicine, Department of Neonatology, Konya, Turkey Phone: +90 5327390934 E-mail: nuriyetarakci@hotmail.com ORCID: orcid.org/0000-0003-2444-4725 Received: 10.01.2020 Accepted: 18.06 .2020

${ }^{(0)}$ Copyright 2021 by Ege University Faculty of Medicine, Department of Pediatrics and Ege Children's Foundation The Journal of Pediatric Research, published by Galenos Publishing House. 
However, to our knowledge, there is no research to date that evaluates the outcomes of the neonatal period of premature babies treated solely in intensive care units. The present study evaluates neonatal outcomes of immigrant preterm babies and compares them with those of Turkish preterm babies.

\section{Materials and Methods}

\section{Study Design and Study Population}

The present study was conducted using a retrospective design in the Neonatal Intensive Care Unit (NICU) of Necmettin Erbakan University, Meram Faculty of Medicine Ethics Committee between October 2015 and October 2019. A total of 240 preterm infants with a gestational age (GA) $\leq 32$ weeks were enrolled. Patients with major congenital anomalies and stillborn infants were not included in the study.

The demographic characteristics of the immigrant and Turkish newborns including nationality, gender, GA, maternal age, maternal or gestational disease, mode of delivery, BW, BW according to GA (small for GA/SGA), antenatal steroid usage and antenatal follow-up were collected from the medical records. Neonatal morbidities were defined as resuscitation in the delivery room, respiratory distress syndrome (RDS), intraventricular hemorrhage (IVH) (grade $>3$ ), sepsis, hemodynamically significant patent ductus arteriosus (PDA), bronchopulmonary dysplasia (BPD), respiratory support [duration of mechanical ventilation, nasal continuous positive airway pressure (nCPAP) and supplemental oxygen], necrotizing enterocolitis (NEC), severe retinopathy of prematurity (ROP) and kangaroo mother care, breastfeeding and catch-up time of birth weight.

GA was determined by either prenatal ultrasound examination, date of last menstrual period or new Ballard. SGA was defined as infants with a BW below the $10^{\text {th }}$ percentile for their GA (5). Sepsis was defined via positive blood culture. Hemodynamically significant PDA was defined according to echocardiography parameters. Left atrium-to-aortic root diameter ratio $\geq 1.4$ in the parasternal long-axis view, ductal diameter $\geq 1.4 \mathrm{~mm} / \mathrm{kg}$ body weight, left ventricular enlargement, and reversed diastolic flow in the descending aorta indicating a significant ductal shunt (6). The antenatal steroid was considered to have been administered if betamethasone therapy was completed 24 hours before delivery. First eye examination was performed at 4 weeks of the chronological age for infants with GA $\geq 27$ weeks, or at 31 weeks of the postmenstrual age (PMA) for infants with GA between 24 and 26 weeks. All assessments for ROP were made by the same pediatric ophthalmologist throughout the study. The staging of ROP was recorded according to the international classification of ROP. The criteria for treatment were: zone 1 any stage of ROP with a plus disease or zone 1 stage 3 without plus and zone 2 stages 2 or 3 with the plus disease as defined by early treatment for the ROP cooperative group (7); severe ROP was defined as ROP requiring treatment. BPD was defined as oxygen requirement at 36-weeks PMA for an infant who was born at $\leq 32$ gestational weeks (8). IVH was based on cranial ultrasonography evaluation in the first week of life according to Volpe criteria (9). Stage 3 patients according to Bell's criteria were defined as NEC. Women who had antenatal examinations at least three times during their pregnancies were followed up antenatally.

\section{Statistical Analysis}

The calculation of the sample size for statistical analysis was performed by taking 20 patients per each variable.

The demographics and incidences of neonatal morbidity among Turkish and immigrant patients were calculated with categorical variables given as frequencies and percentages, and were compared using chi-square or Fisher's tests. The mean and standard deviations or median and first and third quartiles of continuous variables were provided. Continuous variables were compared using the t-test or the MannWhitney $U$ test, where appropriate. The garnered data were analyzed using SAS university edition package version 9.4 (SAS Institute Cary, NC, USA). A p-value of <0.05 was considered significant.

\section{Results}

A total of 240 babies aged $\leq 32$ weeks were included in this study, among which, 64 (26.6\%) were immigrant and 174 (73.4\%) were Turkish. The demographic and clinical data of the patients are summarized in Table I. Maternal age $(p<0.001)$, antenatal follow-up $(p<0.001)$ and antenatal steroid use $(p<0.001)$ were significantly higher in Turkish patients than in those who were immigrants. GA and BW were similar for the two groups. Incidences of SGA $(p=0.04)$ and gestational diabetes $(p=0.01)$ were found to be higher among Turkish babies. The postnatal outcomes of the patients are presented in Table II. RDS ( $p=0.04)$, PDA $(p=0.03)$ and BPD $(p=0.05)$ were statistically higher in the Turkish patients compared to the immigrant patients (Table II). Rates of breastfeeding $(p<0.01)$ and kangaroo mother care $(p<0.01)$ were found to be higher among Turkish mothers. On the other hand, the NEC rate $(p=0.002)$ was 
found to be higher among immigrant babies. The duration of mechanical ventilation and oxygen supply were similar for both groups; however, the duration of nCPAP use was longer in the Turkish patients $(p=0.01)$.

\section{Discussion}

The number of international immigrants has been increasing over recent years. In the broader context of globalization, the increasing volume and complexity of

Table I. Antenatal and natal outcomes of prematurity infants

\begin{tabular}{|c|c|c|c|}
\hline & Turkish citizen $n=176$ & Immigrant $n=64$ & $\mathbf{p}$ \\
\hline Maternal age (mean \pm SD) & $28.2(6.29)$ & $23.4(4.8)$ & $<0.0001$ \\
\hline Gestational age (week) (mean \pm SD) & $29.4(2.48)$ & $29.9(2.16)$ & 0.16 \\
\hline Birth weight (gr) (mean \pm SD) & $1435.1(424.4)$ & $1446.6(356.8)$ & 0.85 \\
\hline Assisted reproductive technigus; $\mathbf{n}(\%)$ & $3(1.17)$ & $2(3.17)$ & 0.61 \\
\hline C/S n (\%) & $118(67.43)$ & $41(65.08)$ & 0.73 \\
\hline SGA n (\%) & $16(9.14)$ & $12(19.05)$ & 0.04 \\
\hline Sex (male) n (\%) & $93(53.14)$ & $38(60.32)$ & 0.33 \\
\hline Multiple pregnancy n (\%) & $52(29.71)$ & $26(41.27)$ & 0.09 \\
\hline No or low frequency of antenatal care $n(\%)$ & $125(71.43)$ & $28(43.75)$ & $<0.0001$ \\
\hline Antenatal steroid n (\%) & $52(29.71)$ & $5(7.94)$ & 0.0005 \\
\hline Preeclampsia n (\%) & $17(9.71)$ & $5(7.94)$ & 0.68 \\
\hline Gestational diabetes mellitus n (\%) & $15(8.57)$ & $0(0)$ & 0.01 \\
\hline Resuscitation n (\%) & $51(29.14)$ & $22(34.92)$ & 0.39 \\
\hline Stillbirth' & $8.8(95 / 10740)$ & $15.2(45 / 2960)$ & 0.003 \\
\hline
\end{tabular}

Table II. Postnatal outcomes of prematurity infants in neonatal intensive care unit

\begin{tabular}{|c|c|c|c|}
\hline & $\begin{array}{l}\text { Turkish citizen } \\
\mathrm{n}=176\end{array}$ & Immigrant $n=64$ & $\mathbf{p}$ \\
\hline RDS n (\%) & $111(63.43)$ & $31(49.21)$ & 0.04 \\
\hline IVH n (\%) & $4(2.68)$ & $1(1.79)$ & 1.00 \\
\hline PDA n (\%) & $21(14.09)$ & $2(3.57)$ & 0.03 \\
\hline NEC n (\%) & $1(0.67)$ & $6(10.71)$ & 0.002 \\
\hline ROP n (\%) & $32(21.48)$ & $8(14.29)$ & 0.25 \\
\hline BPD n (\%) & $30(20.13)$ & $5(8.93)$ & 0.05 \\
\hline Early onset neonatal sepsis n (\%) & $3(2.00)$ & $2(3.57)$ & 0.61 \\
\hline Late onset neonatal sepsis $\mathbf{n}(\%)$ & $15(10.07)$ & $6(10.71)$ & 0.89 \\
\hline Breastfeeding n (\%) & $116(77.33)$ & $17(30.36)$ & $<0.001$ \\
\hline Kangaroo mother care (mean \pm SD) (d) & $114(70.51)$ & $8(14.29)$ & $<0.0001$ \\
\hline Catch-up time of birth weight (mean \pm SD) (d) & $10.05(5.00)$ & $9.73(5.26)$ & 0.69 \\
\hline Oxygen support (median Q1-Q3) (d) & $10.0(4.0-31.0)$ & $7.0(2.50-24.0)$ & 0.28 \\
\hline MV time [median (Q1-Q3)] (d) & $0.0(0.0-4.0)$ & $0.0(0.0-3.5)$ & 0.70 \\
\hline nCPAP time [median (Q1-Q3)] (d) & $2.0(1.0-5.0)$ & $1.0(0.0-2.0)$ & 0.01 \\
\hline
\end{tabular}


flows of migration have led to a wide range of problems in fields including human rights, public health, illness and border control (10). Particularly, the migration of women has been an important component of international migration. The biological status of these women is closely associated with nutrition, reproductive life, the presence of some infections and smoking or alcohol consumption. Statuses of inequalities that cause psychosocial stress such as economic inequality, gender inequality and, in multiethnic societies, ethnic inequality determine the emotional status of these women. All of these influence perinatal health, regardless of why they have become an immigrant (11).

Rates of multiparity, pregnancy-associated complications and negative perinatal outcomes have been reported to be higher among refugees when compared to native populations in some publications (12-15). Raimondi et al. (11) revealed in their study that native mothers have lower birth-weight newborn infants, primiparity, and adolescent pregnancy. They also reported that a larger population of native women in the study compared to the immigrants was effective in this situation (11). However, as an epidemiological paradox, in this research are reported to be better in refugees, although immigrant women tend to face greater demographic and socio-economic risk factors (16).

Group B streptococcal screening during pregnancy in the United States and consequently intrapartum antibiotic prophylaxis reduced the incidence of early-onset sepsis with GBS by $65 \%$ (17). However, the quality of healthcare provided to immigrants living in developed countries has been reported to be inferior to that provided to native populations $(2,18)$. Similar healthcare services are provided for Turkish and immigrant mothers and their babies in Turkey. Antenatal follow-up of immigrant mothers has been observed to be insufficient in the present study. It is likely that the reason for this is not due to the presence of obstacles that prevent immigrant patients from accessing healthcare, but rather due to communication problems and lack of knowledge about antenatal follow-up among patients. In addition, other factors that cause poor antenatal follow-up in the immigrant population are the absence of any problems encountered in the prior pregnancies of multiparous mothers and the absence of a caregiver or a relative to look after other children in the family while their mother attends hospital for follow-up visits. Poor antenatal follow-ups and lack of antenatal corticosteroid use among immigrant mothers brought about a rise in stillbirth rates, requirements for neonatal resuscitation and admission to NICUs consistent with findings which have been reported in the previous literature (3).
Clinical and demographical findings, such as birth weight, week of pregnancy, multiparity and cesarean section birth, were found to be similar in both groups. The number of cesarean section births has been reported to be lower in immigrant patients than in the host citizens in some studies $(19,20)$. However, the cesarean section rate in those studies was calculated including all modes of delivery. In our study, we calculated the rate of cesarean sections only among at-risk babies in neonatal care and found similar rates between the two groups. The maternal age of immigrant patients was found to be lower in the present study, which is compatible with the findings in previous literature (19). Marriage at a young age as a result of conventional family structure, and the desire to escape from the civil war are thought to be related to low maternal age.

Kangaroo mother care results in increased growth and breastfeeding rates of preterm babies (21). Major immunologic components in human milk, such as secretory immunoglobulin-A and growth factors, have a known role in regulating gut barrier integrity and microbial colonization, and therefore, it is protective against the NEC (22). In our study, Kangaroo mother care and breastfeeding rates were found to be quite low among immigrant mothers. This can be attributed to the unwillingness of mothers to participate in baby care, and inefficiency in the evaluation of the importance of breast milk and nursing among immigrant mothers, which could not be improved due to communication problems such as their inability to speak Turkish. Since they have little faith that their preterm babies, admitted to the intensive care unit, will survive, these mothers desire to become mothers again. Furthermore, they may not want to breastfeed their children, as they believe that milking and continuing breastfeeding are methods of birth control.

The adverse neonatal outcomes of $<32$ gestation week preterm babies, including IVH, RDS, neonatal sepsis and $B P D$, have been reported to be associated with ethnic variability (23), although it is difficult to define the effects of ethnicity and race, and this is still a controversial issue (24). The risk of adverse neonatal outcomes after preterm birth among African, Mediterranean and Eastern Asian women is reported to be lower when compared to preterm births among Caucasian European women (23). Incidences of NEC were found to be higher in immigrant babies in the present study, which is considered to be due to the low rate of breastfeeding among immigrant mothers (25). Antenatal follow-up was found to be better, and the rate of antenatal corticosteroid application was higher in Turkish patients. However, incidences of RDS, PDA and BPD were higher in 
Turkish patients when compared to immigrants, which could be attributed to ethnicity and intrauterine stress factors, although further studies are needed to account for the association between ethnicity and neonatal outcome.

\section{Study Limitations}

The retrospective design and small sampling size are the limitations of our study.

\section{Conclusion}

Short-and long-term morbidities of preterm infants in our study differed among Turkish and immigrant patients. We are of the opinion that further studies are needed to determine their association with standards of living, sociocultural status or race.

\section{Ethics}

Ethics Committee Approval: Ethics committee approval was obtained from Necmettin Erbakan University, Meram Faculty of Medicine Ethics Committee (approval number: 2019/1989, date: 12.07.2019).

Informed Consent: Informed consents were not required because the study was conducted retrospectively.

Peer-review: Externally and internally peer-reviewed.

\section{Authorship Contributions}

Surgical and Medical Practices: N.T., Concept: N.T., F.H.Y., Design: N.T., Data Collection or Processing: F.H.Y., Analysis or Interpretation: N.T., Literature Search: N.T., H.A., Writing: N.T., F.H.Y.

Conflict of Interest: No conflict of interest was declared by the authors.

Financial Disclosure: The authors have no financial relationships relevant to this article to disclose.

\section{References}

1. Bollini P, Pampallona S, Wanner P, Kupelnick B. Pregnancy outcome of migrant women and integration policy: a systematic review of the international literature. Soc Sci Med 2009; 68:45261.

2. Cacciani L, Asole S, Polo A, et al. Perinatal outcomes among immigrant mothers over two periods in a region of central Italy. BMC Public Health 2011; 11:294.

3. Malin M, Gissler M. Maternal care and birth outcomes among ethnic minority women in Finland. BMC Public Health 2009; 9:84.

4. Kelly Y, Panico L, Bartley M, Marmot M, Nazroo I, Sacker A. Why does birthweight vary among ethnic groups in the UK? Findings from the Millennium Cohort Study. I Public Health (Oxf) 2009; 31:131-7.
5. Battaglia FC, Lubchenco LO. A practical classification of newborn infants by weight and gestational age. I Pediatr 1967; 71:159-63.

6. Hamrick SE, Hansmann G. Patent ductus arteriosus of the preterm infant. Pediatrics 2010; 125:1020-30.

7. Early Treatment for Retinopathy of Prematurity Cooperative Group. Revised indications for the treatment of retinopathy of prematurity: Results of the early treatment for retinopathy of prematurity randomized trial. Arch Ophthalmol 2003; 121:168494

8. Trembath A, Laughon MM. Predictors of bronchopulmonary dysplasia. Clin Perinatol 2012; 39:585-601.

9. Volpe IJ. Intracranial hemorrhage: Germinal matrix intraventricular hemorrhage of premature infant. In: Volpe II (ed). Neurology of Newborn. 4th ed. Philadelphia, PA: Saunders, 2001; 428-493.

10. Nuzzolese E. Missing people, migrants, identification and human rights. J Forensic Odontostomatol 2012; 30(Suppl 1):4759.

11. Raimondi D, Rey CE, Testa MV, Camoia ED, Torreguitar A, Meritano /. Migrant population and perinatal health. Arch Argent Pediatr 2013; 111:213-7.

12. Alderliesten ME, Vrijkotte TG, Van der Wal MF, Bonsel G). Late start of antenatal care among ethnic minorities in a large cohort of pregnant women. BJOG 2007; 114:1232-9.

13. Lalchandani S, MacQuillan K, Sheil O. Obstetric profiles and pregnancy outcomes of immigrant women with refugee status. Ir Med I 2001; 94:79-80.

14. Essén B, Johnsdotter S, Hovelius B, et al. Qualitative study of pregnancy and childbirth experiences in Somalian women resident in Sweden. BJOG 2000; 107:1507-12.

15. Vangen S, Stoltenberg C, Skrondal A, Magnus P, Stray-Pedersen B. Cesarean section among immigrants in Norway. Acta Obstet Gynecol Scand 2000; 79:553-8.

16. Michaan N, Gil Y, Amzalag S, Laskov I Lessing J, Many A. Perinatal outcome and financial impact of Eritrean and Sudanese refugees delivered in a tertiary hospital in Tel Aviv, Israel. Isr Med Assoc | 2014; 16:371-4.

17. Lin $\mathrm{CY}$, Hsu CH, Huang FY, et al. The Changing Face of EarlyOnset Neonatal Sepsis After the Implementation of a Maternal Group B Streptococcus Screening and Intrapartum Prophylaxis Policy-A Study in One Medical Center. Pediatr Neonatol 2011; 52:78-84.

18. Blais R, Maïga A. Do ethnic groups use health services like the majority of the population? A study from Quebec, Canada.Soc Sci Med 1999; 48:1237-45.

19. Demirci H, Yildirim Topak N, Ocakoglu G, Karakulak Gömleksiz M, Üstünyurt E, Turker AÜ. Birth characteristics of Syrian refugees and Turkish citizens in Turkey in 2015. Int I Gynaecol Obstet 2017; 137:63-6.

20. Huster KM, Patterson N, Schilperoord M, Spiegel P. Cesarean sections among Syrian refugees in Lebanon from december 2012/january 2013 to june 2013: probable causes and recommendations.Yale J Biol Med 2014; 87:269-88.

21. Sharma D, Farahbakhsh N, Sharma S, Sharma P, Sharma A. Role of kangaroo mother care in growth and breast feeding rates in very low birth weight (VLBW) neonates: a systematic review. I Matern Fetal Neonatal Med 2019; 32:129-42. 
22. Nolan LS, Parks OB, Good M. A review of the immunomodulating components of maternal breast milk and protection against necrotizing enterocolitis. Nutrients 2019; 12:14.

23. Schaaf JM, Mol BW, Abu-Hanna A, et al. Ethnic disparities in the risk of adverse neonatal outcome after spontaneous preterm birth. Acta Obstet Gynecol Scand 2012; 91:1402-8.
24. Senior PA, Bhopal R. Ethnicity as a variable in epidemiological research. BMJ 1994; 309:327-30.

25. Colaizy TT, Bartick MC, Jegier B), Ravelli AC). Impact of optimized breastfeeding on the costs of necrotizing enterocolitis in extremely low birthweight Infants. J Pediatr 2016; 175:100-5. 